\title{
Identification and characterisation of vaginal lactobacilli from South African women
}

\author{
Sonal Pendharkar', Tebogo Magopane ${ }^{2}$, Per-Göran Larsson³, Guy de Bruyn², Glenda E Gray², \\ Lennart Hammarström ${ }^{1}$ and Harold Marcotte ${ }^{1,4^{*}}$
}

\begin{abstract}
Background: Bacterial vaginosis (BV), which is highly prevalent in the African population, is one of the most common vaginal syndromes affecting women in their reproductive age placing them at increased risk for sexually transmitted diseases including infection by human immunodeficiency virus-1. The vaginal microbiota of a healthy woman is often dominated by the species belonging to the genus Lactobacillus namely L. crispatus, L. gasseri, L. jensenii and L. iners, which have been extensively studied in European populations, albeit less so in South African women. In this study, we have therefore identified the vaginal Lactobacillus species in a group of 40 African women from Soweto, a township on the outskirts of Johannesburg, South Africa.
\end{abstract}

Methods: Identification was done by cultivating the lactobacilli on Rogosa agar, de Man-Rogosa-Sharpe (MRS) and Blood agar plates with $5 \%$ horse blood followed by sequencing of the $16 \mathrm{~S}$ ribosomal DNA. BV was diagnosed on the basis of Nugent scores. Since some of the previous studies have shown that the lack of vaginal hydrogen peroxide $\left(\mathrm{H}_{2} \mathrm{O}_{2}\right)$ producing lactobacilli is associated with bacterial vaginosis, the Lactobacillus isolates were also characterised for their production of $\mathrm{H}_{2} \mathrm{O}_{2}$.

Results: Cultivable Lactobacillus species were identified in 19 out of 21 women without BV, in three out of five women with intermediate microbiota and in eight out of 14 women with BV. We observed that L. crispatus, L. iners, L. jensenii, $L$. gasseri and L. vaginalis were the predominant species. The presence of $L$. crispatus was associated with normal vaginal microbiota ( $\mathrm{P}=0.024$ ). High level of $\mathrm{H}_{2} \mathrm{O}_{2}$ producing lactobacilli were more often isolated from women with normal microbiota than from the women with $B V$, although not to a statistically significant degree $(P=0.064)$.

Conclusion: The vaginal Lactobacillus species isolated from the cohort of South African women are similar to those identified in European populations. In accordance with the other published studies, L. crispatus is related to a normal vaginal microbiota. Hydrogen peroxide production was not significantly associated to the BV status which could be attributed to the limited number of samples or to other antimicrobial factors that might be involved.

Keywords: Bacterial vaginosis, Lactobacillus, South Africa, Hydrogen peroxide

\section{Background}

The vaginal microbiota of a healthy woman is often dominated by lactobacilli. The most commonly identified Lactobacillus species include L. crispatus, L. gasseri, L. jensenii and L. iners [1-3]. Lactobacilli are thought to play an important role in protecting the host from urogenital infection by lowering the environmental $\mathrm{pH}$ through lactic acid

\footnotetext{
* Correspondence: harold.marcotte@ki.se

'Division of Clinical Immunology, Department of Laboratory Medicine, Karolinska University Hospital, Huddinge, Stockholm, Sweden

${ }^{4}$ Department of Laboratory Medicine, Division of Clinical Immunology, F79, Karolinska Institutet, Stockholm S-141 86, Sweden

Full list of author information is available at the end of the article
}

production, by producing various bacteriostatic and bactericidal substances such as hydrogen peroxide $\left(\mathrm{H}_{2} \mathrm{O}_{2}\right)$ and through competitive exclusion. Decrease in the number of lactobacilli and overgrowth of diverse anaerobes is associated with an increased incidence of bacterial vaginosis (BV) $[4,5]$, which is one of the most common vaginal syndromes among women in their reproductive age [6-8]. BV is associated with an increased susceptibility to sexually transmitted diseases including infection by human immunodeficiency virus-1 (HIV-1) [9-11] where the elevated vaginal $\mathrm{pH}$ associated with $\mathrm{BV}$ may allow the survival of

\section{Biomed Central}

(c) 2013 Pendharkar et al.; licensee BioMed Central Ltd. This is an Open Access article distributed under the terms of the Creative Commons Attribution License (http://creativecommons.org/licenses/by/2.0), which permits unrestricted use, distribution, and reproduction in any medium, provided the original work is properly cited. 
HIV. Moreover, BV associated microbiota has been shown to enhance HIV-1 transcription and replication [12].

It has previously been shown that exogenously applied lactobacilli can persist on the mucosal surface of the vagina, displace BV and restore a normal vaginal microbiota $[13,14]$. Given the high prevalence of BV in women in many sub-Saharan African countries with HIV epidemics (20\%-60\%), colonisation by exogenous lactobacilli may help to reduce the risk of HIV-1 transmission [9]. Furthermore, delivery of a microbicide by lactobacilli colonising the vagina has previously been suggested as a strategy for prevention of HIV transmission, particularly in developing countries [15].

Hence, a better understanding of the species composition and ecology of bacterial ecosystems may help to develop better prophylaxis against BV and HIV. If the Lactobacillus species isolated from African women are similar to those in America and Europe, where probiotic studies have been performed, similar strategies utilising probiotic and engineered lactobacilli could be applied in Africa. Some studies reported differences in the composition of vaginal microbiota among different ethnic groups in North America, where a higher incidence of vaginal communities not dominated by lactobacilli was observed in black women [16,17]. However, the few studies performed in Africa to date suggest that the vaginal Lactobacillus species predominant among black women are similar to those dominating in American and European studies [18,19].

In preparation to study the colonisation efficiency of exogenously applied vaginal lactobacilli and to treat BV in South African women, we have therefore identified the cultivable vaginal Lactobacillus species in women with or without BV in Soweto.

\section{Methods \\ Sample collection}

Forty premenopausal and HIV uninfected black women aged 18-44 years with or without BV were recruited for the study. Study participants were randomly selected among women who visited the Perinatal HIV Research Unit (PHRU) in Chris Hani Baragwanath Hospital, Soweto and received voluntary HIV counseling and testing. Inclusion criteria were their willingness to provide the informed consent, passing the assessment of understanding, BHCG negative status (non-pregnant) and belonging to a low risk group for HIV acquisition. The women were non-menstruating and not taking antibiotics at the time of sample collection. Vaginal swabs were collected in Amies agar gel medium with charcoal (Copan Venturi Transsystem ${ }^{\circledR}$ Copan Diagnostics, Italy). Simultaneously, a second similar swab was used to prepare a smear on a glass slide for BV scoring. The ethical approval for collection of swab samples was granted by
Human Research Ethics Committee (Medical), University of the Witwatersrand, Johannesburg (Ethical permit number M011138). A regional ethical permit was also granted by Regionala Etikprövningdnämnden, Stockholm, for analysing these samples (Diarienummer: 2012/1362-31/1).

\section{Cultivation of lactobacilli}

The swabs were transported at room temperature to the laboratory in Sweden within a maximum of two days. The swabs were directly streaked onto Rogosa agar (BD Difco $^{\text {тм }}$ Rogosa SL agar, Becton, Dickinson and Company, Spark, MD), Columbia agar (BD Difco ${ }^{\text {TM }}$ Columbia Blood Agar Base) with 5\% horse blood and de Man-RogosaSharpe (MRS) agar (BD Difco ${ }^{\mathrm{TM}}$ Lactobacilli MRS broth) within 24 hours of arrival. The swabs were then vortexed in $1 \mathrm{ml}$ sterile PBS ( $\mathrm{pH} \mathrm{7.4)}$ to prepare bacterial suspensions. The bacterial suspensions were diluted tenfold serially (three dilutions per suspension) and each dilution $(100 \mu \mathrm{l})$ was plated onto the three different agar plates as described above [20]. Plates were incubated for 48 hours at $37^{\circ} \mathrm{C}$ in an incubator in anaerobic condition using BD GasPack $^{\text {TM }}$ EZ gaz generating systems (Becton, Dickinson and Company, Sparks, MD). Colonies with different morphology yielding variable rods were re-streaked. Respective colonies from re-streaked plates were Gram stained and the colonies with Gram positive rods were used to inoculate the MRS broth medium. Small transparent colonies from blood agar plates yielding Gram positive bacilli not growing in MRS broth were collected directly from the plates and used for genomic DNA isolation. Glycerol stocks $(15 \%)$ were prepared and stored at $-80^{\circ} \mathrm{C}$. Eight to 12 different colonies were picked per sample.

\section{Identification of lactobacilli}

Genomic DNA was extracted from lactobacilli using Qiagen's DNAeasy Blood \& Tissue extraction kit (Qiagen $\mathrm{GmbH}$, Hilden, Germany). The isolates were identified to the species level by sequencing the $16 \mathrm{~S}$ ribosomal RNA (rRNA) gene as described previously [21]. Briefly, the complete $16 \mathrm{~S}$ rRNA gene $(1.5 \mathrm{~kb})$ was amplified by PCR using the primers P0 (5'-GAGAGTTTGATCCTGGCT CAG-3') and P6 (5'-CTACGGCTACCTTGTTACGA-3') and sequenced. The obtained sequences were then subjected to nucleotide-nucleotide BLAST using BLASTN (http://www.ncbi.nlm.nih.gov/) and subsequently compared to the 16SrRNA sequences of typed strains to validate the results. The identification of Lactobacillus species was considered confirmed if the sequences showed 99-100\% homology with the typed strain. The following typed strains and $16 \mathrm{~S}$ rRNA gene sequence (Genbank accession number) were used for the comparisons: L. mucosae strain CCUG 43179 (AF126738), L. paracasei strain ATCC 25302 (HQ423165), L. ruminis strain ATCC 27782 (CP003032) and NBRC 102161 (AB326354), L. crispatus strain ATCC 
33820 (AF257097) \& DSM 20584T (FR683088), L. coleohominis DSM 14060 (AM113776), L. vaginalis strain ATCC 49540 (AF243177) and KC19 (AF243154), L. iners strain DSM 13335 (NR_036982) and CCUG 28746T (Y16329), L. gasseri ATCC 33323 (AF519171) and L. jensenii strain ATCC 25258 (AF243176).

\section{Determination of BV}

Vaginal smears were Gram stained and graded on a 10 point scale based on the presence of lactobacilli and other anaerobes as described by Nugent [22] for normal microbiota (score 0-3), intermediate microbiota (score 4-6) and BV (score 7-10). In brief, a score of zero to four is given individually for the presence of lactobacilli and for Gardnerella/Bacteroides morphotypes and a score of zero to two for curved Gram variable rods. The sum of all scores is a representative of the BV score. The presence of epithelial cells covered with bacteria (clue cells), a critical component of the Amsel's clinical criteria for BV, was also noted [23].

\section{Hydrogen peroxide $\left(\mathrm{H}_{2} \mathrm{O}_{2}\right)$ production test}

Lactobacillus isolates were streaked onto a $20 \mathrm{ml}$ MRS

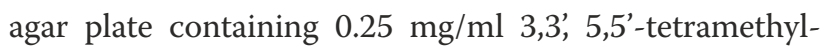
benzidine (TMB) (Sigma-Aldrich, St-Louis, MO) and $0.01 \mathrm{mg} / \mathrm{ml}$ of horseradish peroxidase (HRP) (SigmaAldrich). Plates were incubated in anaerobic condition using the BD Gas Pack ${ }^{\mathrm{TM}}$ anaerobic container system for 72 hours and were exposed to air for 30 minutes before scoring them for blue coloration. HRP generates $\mathrm{O}_{2}$ from any $\mathrm{H}_{2} \mathrm{O}_{2}$ produced by the lactobacilli which in turn oxidises the TMB substrate to form a blue pigment. On the basis of the blue coloration, isolates were scored for $\mathrm{H}_{2} \mathrm{O}_{2}$ production as 0 for no blue coloration, 1 for light blue, 2 for moderate and 3 for dark blue coloration. Since it was difficult to culture $L$. iners on MRS agar medium, $L$. iners isolates were not included in the $\mathrm{H}_{2} \mathrm{O}_{2}$ production test.

\section{Statistical analysis}

Fisher's exact test was performed to test the relation between BV status (normal microbiota vs. BV) and the presence of any lactobacilli, specific Lactobacillus species and high/low $\mathrm{H}_{2} \mathrm{O}_{2}$-producing lactobacilli. Two-tailed $\mathrm{P}$ values less than 0.05 were considered statistically significant. All the comparisons were performed with GraphPad Prism 4 software (GraphPad Software, Inc., La Jolla, Ca).

\section{Results}

\section{BV status and Lactobacillus colonisation}

Nugent scoring of the Gram stained vaginal smears revealed that 21 women had a normal vaginal microbiota, five had an intermediate microbiota and 14 had BV. The presence of clue cells was observed in all the women with BV but not in women with normal or intermediate microbiota (Table 1). Lactobacillus colonisation was observed in women both with and without BV, where cultivable Lactobacillus species were identified in 19 out of 21 women with normal microbiota, in three out of five women with intermediate microbiota and in eight out of 14 women with BV.

A total of 196 isolates were cultured from 40 swabs and 30 women $(75 \%)$ were identified with cultivable Lactobacillus species. L. crispatus, L. iners and L. gasseri were identified in $10(33 \%), 8(27 \%)$ and 7 (23\%) women respectively, whereas $L$. vaginalis and $L$. jensenii colonised five (17\%) women each. These were the most commonly identified Lactobacillus species. Other Lactobacillus species identified were $L$. ruminis, $L$. mucosae, $L$. paracasei and L. coleohominis (Figure 1). Among the 30 women harbouring lactobacilli, nine were colonised by more than one Lactobacillus species (Table 2). L. crispatus was only isolated from women with normal microbiota whereas the other predominant Lactobacillus species (L. jensenii, L. gasseri, L. vaginalis and L. iners) were isolated from women both with and without BV (Figure 2). The two women who were colonised by L. ruminis only and the one woman who was colonized by a mix of $L$. ruminis, $L$. mucosae and $L$. paracasei were identified with $\mathrm{BV}$ and intermediate microbiota, respectively. Colonisation by any lactobacilli and in particular L. crispatus was significantly associated with a normal vaginal microbiota (Fisher test, normal vs. $\mathrm{BV}$ microbiota, $\mathrm{P}=0.0386$ and $\mathrm{P}=0.024$ respectively) but not the colonisation by other Lactobacillus species.

\section{Hydrogen peroxide $\left(\mathrm{H}_{2} \mathrm{O}_{2}\right)$ production and BV status}

All the isolates but $L$. iners were tested and scored for $\mathrm{H}_{2} \mathrm{O}_{2}$ production on a scale of zero to three on the basis of blue coloration. $L$. iners was not evaluated for $\mathrm{H}_{2} \mathrm{O}_{2}$ production since they do not grow on MRS agar plates. Production of $\mathrm{H}_{2} \mathrm{O}_{2}$ was observed in the majority of the L. crispatus $(90 \%), L$. jensenii $(86 \%)$ and $L$. vaginalis (80\%) isolates and in a lower proportion of the L. gasseri isolates (30\%). L. ruminis, L. coleohominis, L. paracasei were non-producers. Among the most commonly isolated species, the proportion of isolates producing high levels of $\mathrm{H}_{2} \mathrm{O}_{2}$ (score 2 and 3) was significantly higher (Fisher test, $\mathrm{P}<0.001)$ for $L$. jensenii (52\%), L. crispatus (33 \%) and L. vaginalis $(79 \%)$ than L. gasseri $(0 \%)$.

The isolation of strong $\mathrm{H}_{2} \mathrm{O}_{2}$ producers (either $L$. jensenii, L. crispatus or L. vaginalis with a score of 2 or 3 ) was in general more frequent in women with a normal microbiota than in the women with an intermediate microbiota or BV. However $\mathrm{H}_{2} \mathrm{O}_{2}$ production as an individual factor did not contribute significantly to the normal vaginal microbiota (Fisher test, normal Vs. BV microbiota, $\mathrm{P}=0.064$ ) (Figure 3). 
Table 1 Study participants characteristics

\begin{tabular}{lcccc}
\hline & Normal & Intermediate & BV & $\begin{array}{c}\text { Women } \\
\text { Total }\end{array}$ \\
& $\mathbf{N = 2 1}$ & $\mathbf{N = 5}$ & $\mathbf{N = 1 4}$ & $\mathbf{4 0}$ \\
\hline Mean age (range) & $\begin{array}{l}27 \\
(19-40)\end{array}$ & $\begin{array}{c}29 \\
(22-40)\end{array}$ & $\begin{array}{c}27 \\
(19-44)\end{array}$ & $\begin{array}{c}27 \\
(18-44)\end{array}$ \\
$\begin{array}{l}\text { Median (and range) of } \\
\text { Nugent scores }\end{array}$ & $5(4-6)$ & $8(8-10)$ & \\
$\begin{array}{l}\text { Number of samples with } \\
\text { clue cells }\end{array}$ & 0 & 0 & 14 & 14 \\
$\begin{array}{l}\text { Presence of Gardnerella } \\
\text { morphotypes on } \\
\text { microscopy }\end{array}$ & 0 & 5 & 14 & 19 \\
$\begin{array}{l}\text { Presence of Mobiluncus } \\
\text { morphotypes on } \\
\text { microscopy }\end{array}$ & 0 & 0 & 3 & 3 \\
$\begin{array}{l}\text { Presence of any } \\
\text { Lactobacillus species on } \\
\text { culture }\end{array}$ & 19 & 3 & 8 & 30 \\
$\begin{array}{l}\text { Presence of L. crispatus } \\
\text { on culture }\end{array}$ & 10 & 0 & 0 & 10 \\
\hline
\end{tabular}

\section{Discussion}

With an increasing number of HIV-1 infected individuals and women being at a higher risk of acquiring HIV infection, it is of great importance to improve women's vaginal health especially in the high risk population for sexually transmitted diseases. It is estimated that nearly one-third of all new HIV cases in South African population might be prevented if all cases of BV could be cured [9]. With an aim to restore the vaginal health through the administration of exogenous Lactobacillus among South African women, it was important to identify the Lactobacillus species that colonise women in this region. Our finding indicates that the Lactobacillus species (L. crispatus, L. iners, $L$. gasseri, $L$. vaginalis and $L$. jensenii) that dominate the vaginal microbiota in our cohort are similar to those predominating in European and American women [1,2,24]. Our results are in accordance with studies conducted by
Table 2 Colonising Lactobacillus species in thirty women

\begin{tabular}{lcccc}
\hline Colonising species & $\begin{array}{c}\text { No. of } \\
\text { women }\end{array}$ & \multicolumn{3}{c}{ Nugent score } \\
\cline { 5 - 6 } colonised & $\mathbf{0 - 3}$ & $\mathbf{4 - 6}$ & $\mathbf{7 +}$ \\
\hline L. crispatus & 4 & 4 & & \\
L. iners & 7 & 4 & 1 & 2 \\
L. gasseri & 4 & 2 & 1 & 1 \\
L. jensenii & 2 & 1 & & 1 \\
L. vaginalis & 2 & 1 & & 1 \\
L. ruminis & 2 & & & 2 \\
L. crispatus, L. jensenii & 2 & 2 & & \\
L. crispatus, L. gasseri & 1 & 1 & & \\
L. crispatus, L. vaginalis & 1 & 1 & & \\
L. crispatus, L. coleohominis & 1 & 1 & & \\
L. iners, L. vaginalis & 1 & 1 & & \\
L. crispatus, L. vaginalis, L. gasseri & 1 & 1 & & \\
L. mucosae, L. paracasei, L. ruminis & 1 & & 1 & \\
L. gasseri, L. jensenii & 1 & &
\end{tabular}

Akunam et al. [19] in Nigeria and more recently, Damelin et al. in South Africa [18], where the same predominant vaginal Lactobacillus species were isolated.

As previously reported, the presence of Lactobacillus species was a major determinant of a normal vaginal microbiota [25,26]. More particularly, the isolation of L. crispatus was strongly associated with the normal vaginal microbiota of women in the study as none of the women colonised by L. crispatus had BV or an intermediate microbiota. A number of previous studies have also shown an association between absence of BV and the presence of L. crispatus [1,2,24]. Furthermore, longitudinal analysis of the microbiota has shown that the presence of $L$. crispatus promotes stability of the vaginal microbiota [26]. The ability of $L$. crispatus to produce $\mathrm{H}_{2} \mathrm{O}_{2}$ has been suggested as an important factor in maintaining the normal vaginal mirobiota as most of the

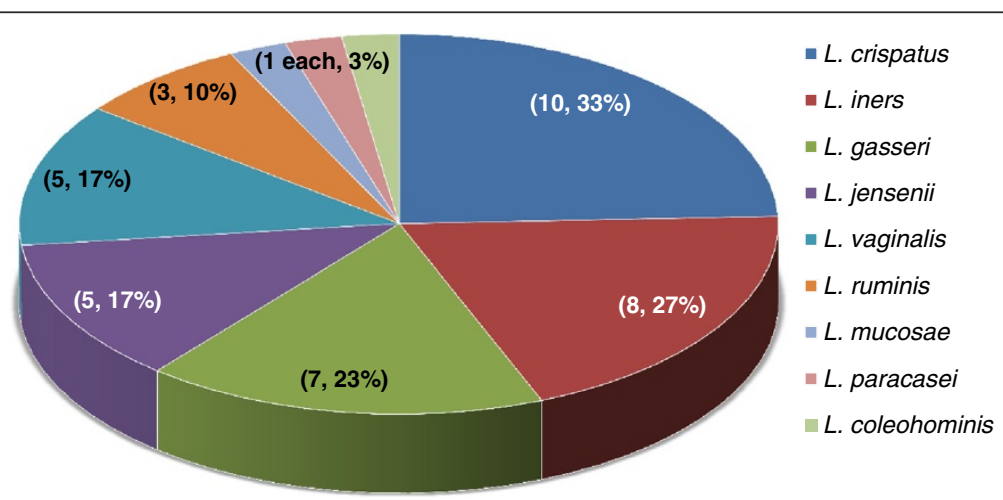

Figure 1 Distribution of colonising Lactobacillus species in South African women. The number and percentage of women colonised by the Lactobacillus species is indicated in parenthesis. 


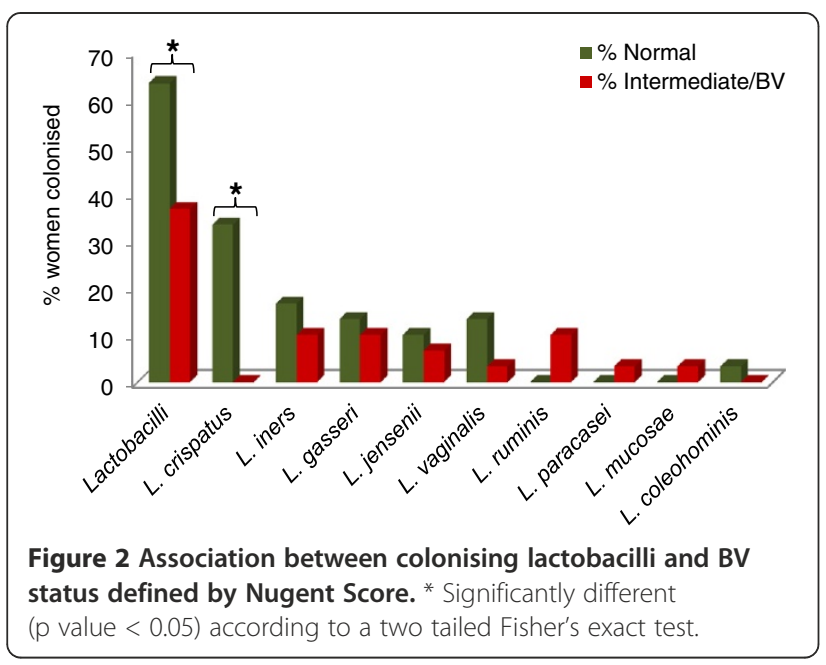

L. crispatus strains were found to be strong $\mathrm{H}_{2} \mathrm{O}_{2}$ producers [5]. On the contrary, L. iners, L. gasseri and $L$. jensenii were isolated from women with normal microbiota and BV. The presence of these Lactobacillus species in women with BV could be due to their poorer colonisation resistance, thereby allowing overgrowth of other bacteria or due to their better resistance for the environmental conditions associated with BV. Longitudinal studies in pregnant women have shown that the women harboring these Lactobacillus species, particularly $L$. gasseri and $L$. iners, are more susceptible to BV compared to the women colonised by L. crispatus [26]. It has also been suggested that $L$. iners may become a dominant part of the vaginal microbiota when the microbiota is in a transitional stage between abnormal and normal [27].

The vast majority of clinical studies have established an inverse association between $\mathrm{BV}$ and the occurrence of vaginal $\mathrm{H}_{2} \mathrm{O}_{2}$-producing Lactobacillus species. In a 2year follow-up study, Hawes et al. documented that the acquisition of bacterial vaginosis was strongly associated with a lack or loss of hydrogen peroxide producing lactobacilli [5]. Although the results of the numerous clinical studies suggest that BV is caused by the lack of

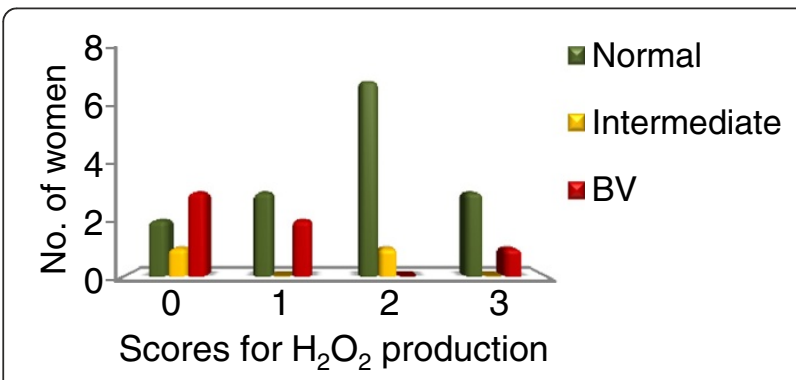

Figure 3 Relation between hydrogen peroxide production by lactobacilli and the Nugent score. vaginal $\mathrm{H}_{2} \mathrm{O}_{2}$-producing Lactobacillus species; the established correlation may not necessarily indicate causality. Lactobacilli that produce $\mathrm{H}_{2} \mathrm{O}_{2}$ have been shown in vitro to inhibit the growth of various microorganisms, including Gardnerella vaginalis, anaerobes, Neisseria gonorrhoeae as well as the survival of HIV [28-31], but the relative contribution of the $\mathrm{H}_{2} \mathrm{O}_{2}$ produced by the Lactobacillus species to the overall antimicrobial effect is still a matter of debate. Under the hypoxic conditions that generally prevail in the vagina, $\mathrm{H}_{2} \mathrm{O}_{2}$ production by vaginal lactobacilli is undetectable (detection threshold $10 \mathrm{nM}$ ). Additionally, studies have shown that the cervicovaginal fluid and semen have a significant $\mathrm{H}_{2} \mathrm{O}_{2}$-blocking activity and that physiological concentrations of $\mathrm{H}_{2} \mathrm{O}_{2}$ below $100 \mu \mathrm{M}$ did not kill any of the tested BV-associated bacteria [32].

In this study, we found that the majority of L. crispatus, $L$. jensenii and $L$. vaginalis isolates from South African women were producing $\mathrm{H}_{2} \mathrm{O}_{2}$, corroborating previous results [33,34]. Similar to the other reports, we have also observed that a high proportion of $L$. crispatus, $L$. jensenii and $L$. vaginalis isolates were strong $\mathrm{H}_{2} \mathrm{O}_{2}$ producers while all the $L$. gasseri isolates were low producers $[24,30,33,35]$. The presence of these strong $\mathrm{H}_{2} \mathrm{O}_{2}$ producers was higher in women with a normal microbiota although not to a significant level. The absence of significant inverse association between $\mathrm{BV}$ and the occurrence of vaginal $\mathrm{H}_{2} \mathrm{O}_{2}$-producing Lactobacillus species in the present study could be due to different factors. Our sample size was rather small and a single sampling occasion may not properly reflect the status of the vaginal microbiota of a woman as changes in the microflora during the menstrual cycle has been documented previously. Several studies have indicated that Lactobacillus growth increases throughout the menstrual cycle, but decreases during the menses $[36,37]$. Furthermore, we did not record any behavioral factors that might have affected the vaginal microbiota status during the study. Therefore, our results need to be confirmed in a larger cohort preferably using a longitudinal study design, combined with data on subjects' behaviors.

The production of $\mathrm{H}_{2} \mathrm{O}_{2}$ by L. iners isolates was not evaluated as these strains grow poorly on MRS containing TMB substrate. Most $L$. iners strains have been found to be non- $\mathrm{H}_{2} \mathrm{O}_{2}$ producers which might correlate with our finding that these species was isolated in both $\mathrm{BV}$ positive and negative women [33]. The production of $\mathrm{H}_{2} \mathrm{O}_{2}$ in this species should be assessed on medium adapted for the growth of $L$. iners. Furthermore, the proportion of $\mathrm{H}_{2} \mathrm{O}_{2}$ producing lactobacilli (and not only their presence) might also be important and the relative amount of lactobacilli should be determined by molecular methods. Finally, although the production of $\mathrm{H}_{2} \mathrm{O}_{2}$ by lactobacilli maybe an important factor for maintenance of the vaginal microbiota, other factors such as 
competition for adherence and production of other antimicrobial substances may also contribute to vaginal health and might act in synergy with $\mathrm{H}_{2} \mathrm{O}_{2}$. Comparative genomic studies of the lactobacilli isolated from the vagina of women with normal microbiota and BV might give a clue of the factors involved in colonisation resistance.

\section{Conclusions}

The vaginal Lactobacillus species identified in black South African women from Soweto are similar to those identified in women from European populations. Colonising Lactobacillus species, in particular L. crispatus, contribute to a normal vaginal microbiota. High $\mathrm{H}_{2} \mathrm{O}_{2}$ producers were more frequently isolated from women without BV, although not to a statistically significant degree which might be due to the small sample size. The similarity in the species composition between European and African women suggest that, similar to the studies conducted in North European populations [12,21], administration of exogenously applied lactobacilli (probiotic or designer probiotics) in South African women could potentially be used for treatment of BV and thus reduce the occurrence of infection by sexually transmitted pathogens, including HIV-1.

\section{Abbreviations}

BV: Bacterial Vaginosis; HIV-1: Human immunodeficiency virus-1; $\mathrm{H}_{2} \mathrm{O}_{2}$ : Hydrogen peroxide; TMB: 3,3', 5,5'-tetramethylbenzidine; HRP: Horseradish peroxidase.

\section{Competing interests}

The authors declare that they have no competing interests.

\section{Authors' contributions}

GEG, GdB, HM, LH designed the research project, SP, TM and PL performed the experiments. Statistical analysis was performed by SP, HM and PG and the paper was written by SP, HM and LH. All authors read and approved the final manuscript.

\section{Acknowledgements}

The study was supported by an international collaborative research grant funded by the Swedish International Development Cooperation Agency (Sida) (Swedish Research Links Programme) and the National Research Foundation of South Africa. The South African AIDS Vaccine Initiative provided funding for the screening protocol.

\section{Author details}

'Division of Clinical Immunology, Department of Laboratory Medicine, Karolinska University Hospital, Huddinge, Stockholm, Sweden. ${ }^{2}$ Perinatal HIV Research Unit (PHRU), Chris Hani Baragwanath Hospital, Soweto, Johannesburg, South Africa. ${ }^{3}$ Department of Obstetrics and Gynaecology Kärnsjukhuset, Skaraborg hospital and University of Skövde, Skövde SE-541 85 , Sweden. ${ }^{4}$ Department of Laboratory Medicine, Division of Clinical Immunology, F79, Karolinska Institutet, Stockholm S-141 86, Sweden.

Received: 11 July 2012 Accepted: 18 January 2013

Published: 26 January 2013

\section{References}

1. Antonio MA, Hawes SE, Hillier SL: The identification of vaginal Lactobacillus species and the demographic and microbiologic characteristics of women colonized by these species. J Infect Dis 1999, 180:1950-1956.
2. Vásquez A, Jakobsson T, Ahrné S, Forsum U, Molin G: Vaginal lactobacillus biota of healthy Swedish women. J Clin Microbiol 2002, 40:2746-2749.

3. Verhelst R, Verstraelen H, Claeys G, Verschraegen G, Delanghe J, Van Simaey L, De Ganck C, Temmerman M, Vaneechoutte M: Cloning of $16 \mathrm{~S}$ rRNA genes amplified from normal and disturbed vaginal microbiota suggests a strong association between Atopobium vaginae, Gardnerella vaginalis and bacterial vaginosis. BMC Microbiol 2004, 4:16.

4. Cherpes TL, Hillier SL, Meyn LA, Busch JL, Krohn MA: A delicate balance: risk factors for acquisition of bacterial vaginosis include sexual activity, absence of hydrogen peroxide-producing lactobacilli, black race, and positive herpes simplex virus type 2 serology. Sex Transm Dis 2008, 35:78-83.

5. Hawes SE, Hillier SL, Benedetti J, Stevens CE, Koutsky LA, Wolner-Hanssen $P$, Holmes KK: Hydrogen peroxide-producing lactobacilli and acquisition of vaginal infections. J Infect Dis 1996, 174:1058-1063.

6. Spiegel CA: Bacterial vaginosis. Clin Microbiol Rev 1991, 4:485.

7. Koumans EH, Sternberg M, Bruce C, McQuillan G, Kendrick J, Sutton M Markowitz LE: The prevalence of bacterial vaginosis in the United States, 2001-2004; associations with symptoms, sexual behaviors, and reproductive health. Sex Transm Dis 2007, 34:864-869.

8. Taha TE, Gray RH, Kumwenda NI, Hoover DR, Mtimavalye LA, Liomba GN, Chiphangwi JD, Dallabetta GA, Miotti PG: HIV infection and disturbances of vaginal flora during pregnancy. J Acquir Immune Defic Syndr Hum Retrovirol 1999, 20:52-59.

9. Myer L, Denny L, Telerant R, de SM, Wright TC Jr, Kuhn L: Bacterial vaginosis and susceptibility to HIV infection in South African women: a nested case-control study. J Infect Dis 2005, 192:1372-1380.

10. Taha TE, Hoover DR, Dallabetta GA, Kumwenda NI, Mtimavalye LA, Yang LP, Liomba GN, Broadhead RL, Chiphangwi JD, Miotti PG: Bacterial vaginosis and disturbances of vaginal biota: association with increased acquisition of HIV. AIDS 1998, 12:1699-1706.

11. van de Wijgert JHHM, Morrison CS, Brown J, Kwok C, Van Der Pol B, Chipato T, Byamugisha JK, Padian N, Salata RA: Disentangling contributions of reproductive tract infections to HIV acquisition in African Women. Sex Transm Dis 2009, 36:357-364.

12. Al-Harthi L, Roebuck KA, Olinger GG, Landay A, Sha BE, Hashemi FB, Spear GT: Bacterial vaginosis-associated microbiota isolated from the female genital tract activates HIV-1 expression. J Acquir Immune Defic Syndr 1999, 21:194-202

13. Marcone V, Calzolari E, Bertini M: Effectiveness of vaginal administration of Lactobacillus rhamnosus following conventional metronidazole therapy: how to lower the rate of bacterial vaginosis recurrences. New Microbiol 2008, 31:429-433.

14. Larsson P-G, Stray-Pedersen B, Ryttig KR, Larsen S: Human lactobacilli as supplementation of clindamycin to patients with bacterial vaginosis reduce the recurrence rate; a 6-month, double-blind, randomized, placebo-controlled study. BMC Womens Health 2008, 8:3.

15. Chang TL-Y, Chang C-H, Simpson DA, Xu Q, Martin PK, Lagenaur LA, Schoolnik GK, Ho DD, Hillier SL, Holodniy M, Lewicki JA, Lee PP: Inhibition of HIV infectivity by a natural human isolate of Lactobacillus jensenii engineered to express functional two-domain CD4. Proc Natl Acad Sci USA 2003, 100:11672-11677.

16. Ravel J, Gajer P, Abdo Z, Schneider GM, Koenig SSK, McCulle SL, Karlebach S, Gorle R, Russell J, Tacket CO, Brotman RM, Davis CC, Ault K, Peralta L, Forney L: Vaginal microbiome of reproductive-age women. Proc Natl Acad Sci USA 2011, 108(1):4680-4687.

17. Zhou X, Brown CJ, Abdo Z, Davis CC, Hansmann MA, Joyce P, Foster JA, Forney LJ: Differences in the composition of vaginal microbial communities found in healthy Caucasian and black women. ISME J 2007, 1:121-133.

18. Damelin LH, Paximadis M, Mavri-Damelin D, Birkhead M, Lewis DA, Tiemessen $C T$ : Identification of predominant culturable vaginal Lactobacillus species and associated bacteriophages from women with and without vaginal discharge syndrome in South Africa. J Med Microbiol 2011, 60:180-183.

19. Anukam KC, Osazuwa EO, Ahonkhai I, Reid G: Lactobacillus vaginal microbiota of women attending a reproductive health care service in Benin city, Nigeria. Sex Transm Dis 2006, 33:59-62.

20. Ehrström S, Daroczy K, Rylander E, Samuelsson C, Johannesson U, Anzén B, Påhlson C: Lactic acid bacteria colonization and clinical outcome after probiotic supplementation in conventionally treated bacterial vaginosis and vulvovaginal candidiasis. Microbes Infect 2010, 12:691-699. 
21. Köll-Klais P, Mändar R, Leibur E, Marcotte H, Hammarström L, Mikelsaar M: Oral lactobacilli in chronic periodontitis and periodontal health: species composition and antimicrobial activity. Oral Microbiol Immunol 2005, 20:354-361.

22. Nugent RP, Krohn MA, Hillier SL: Reliability of diagnosing bacterial vaginosis is improved by a standardized method of gram stain interpretation. J Clin Microbiol 1991, 29:297-301.

23. Lin DP, Pan BJ, Fuh JC, Huang TH: Improving Gram-stained reproducible result by further adding clue cells in diagnosing bacterial vaginosis. Kaohsiung J Med Sci 2002, 18:164-170.

24. Wilks M, Wiggins $R$, Whiley A, Hennessy E, Warwick S, Porter $H$, Corfield A, Millar M: Identification and $\mathrm{H}_{2} \mathrm{O}_{2}$ production of vaginal lactobacilli from pregnant women at high risk of preterm birth and relation with outcome. J Clin Microbiol 2004, 42:713-717.

25. Boris S, Suárez JE, Vázquez F, Barbés C: Adherence of human vaginal lactobacilli to vaginal epithelial cells and interaction with uropathogens. Infect Immun 1998, 66:1985-1989.

26. Verstraelen H, Verhelst R, Claeys G, De Backer E, Temmerman M, Vaneechoutte M: Longitudinal analysis of the vaginal microbiota in pregnancy suggests that $L$. crispatus promotes the stability of the normal vaginal microbiota and that $L$. gasseri and/or $L$. iners are more conducive to the occurrence of abnormal vaginal microbiota. BMC Microbiol 2009, 9:116.

27. Jakobsson T, Forsum U: Lactobacillus iners: a marker of changes in the Vaginal Flora? J Clin Microbio/ 2007, 45:3145

28. Skarin A, Sylwan J: Vaginal lactobacilli inhibiting growth of Gardnerella vaginalis, Mobiluncus and other bacterial species cultured from vaginal content of women with bacterial vaginosis. Acta Pathol Microbiol Immunol Scand B 1986, 94:399-403.

29. Klebanoff S, Hiller S, Eschenbach D, Waltersdorph A: Control of the microbial-flora of the vagina by $\mathrm{H} 2 \mathrm{O} 2$-generating lactobacilli. J Infect Dis 1991, 164:94-100.

30. Zheng $\mathrm{H}$, Alcorn T, Cohen M: Effects of H2O2-producing lactobacilli on Neisseria-gonorrhoeae growth and catalase activity. J Infect Dis 1994, 170:1209-1215.

31. Coombs RW, Klebanoff SJ: Viricidal effect of Lactobacillus acidophilus on human immunodeficiency virus type 1: possible role in heterosexual transmission. J Exp Med 1991, 174:289-292.

32. O'Hanlon DE, Moench TR, Cone RA: In vaginal fluid, bacteria associated with bacterial vaginosis can be suppressed with lactic acid but not hydrogen peroxide. BMC Infect Dis 2011, 11:200.

33. Antonio MAD, Rabe LK, Hillier SL: Colonization of the rectum by Lactobacillus species and decreased risk of bacterial vaginosis. J Infect Dis 2005, 192:394-398.

34. Vallor AC, Antonio MA, Hawes SE, Hillier SL: Factors associated with acquisition of, or persistent colonization by, vaginal lactobacilli: role of hydrogen peroxide production. J Infect Dis 2001, 184:1431-1436.

35. Song $Y L$, Kato N, Matsumiya Y, Liu CX, Kato H, Watanabe K: Identification of and hydrogen peroxide production by fecal and vaginal lactobacilli isolated from Japanese women and newborn infants. J Clin Microbiol 1999, 37:3062-3064.

36. Lopes dos Santos Santiago G, Cools P, Verstraelen H, Trog M, Missine G, Aila NE, Verhelst R, Tency I, Claeys G, Temmerman M, Vaneechoutte M: Longitudinal study of the dynamics of vaginal microflora during two consecutive menstrual cycles. PLoS One 2011, 6:e28180.

37. Srinivasan S, Liu C, Mitchell CM, Fiedler TL, Thomas KK, Agnew KJ, Marrazzo JM, Fredricks DN: Temporal variability of human vaginal bacteria and relationship with bacterial vaginosis. PLoS One 2010, 5:e10197.

doi:10.1186/1471-2334-13-43

Cite this article as: Pendharkar et al: Identification and characterisation of vaginal lactobacilli from South African women. BMC Infectious Diseases 2013 13:43

\section{Submit your next manuscript to BioMed Central and take full advantage of:}

- Convenient online submission

- Thorough peer review

- No space constraints or color figure charges

- Immediate publication on acceptance

- Inclusion in PubMed, CAS, Scopus and Google Scholar

- Research which is freely available for redistribution 